|| ISSN(online): 2589-8698 || ISSN(print): 2589-868X ||

International Journal of Medical and Biomedical Studies Available Online at www.ijmbs.info

NLM (National Library of Medicine ID: 101738825)

Index Copernicus Value 2019: 79.34

Original Research Article

Volume 5, Issue 8; August: 2021; Page No. 339-342

\title{
GASTRIC ASPIRATE: A SCREENING TOOL FOR DETECTION OF EARLY NEONATAL SEPSIS-A PROSPECTIVE STUDY IN TERTIARY CARE CENTRE, INDORE
}

\author{
Dr. Mansi Gupta ${ }^{1}$, Dr. Vivek Singh Kirar ${ }^{2}$, Dr. Sanjeev Narang ${ }^{3}$, Dr. Swati Prashant ${ }^{4}$ \\ PG Resident $3^{\text {rd }}$ Year $^{1}$ (Dept. of Pathology), PG Resident $3^{\text {rd }}$ Year $^{2}$ (Dept. of Paediatrics), \\ Professor \& HOD ${ }^{3}$ (Dept. of Pathology), Professor \& HOD ${ }^{4}$ (Dept. of Paediatrics) \\ Department of Paediatrics, Index Medical College Hospital and Research Centre, Indore $2 \& 4$ \\ Department of Pathology, Index Medical College Hospital and Research Centre, Indore ${ }^{1 \& 3}$
}

Article Info: Received 18June 2021; Accepted 27 August 2021

DOI: https://doi.org/10.32553/ijmbs.v5i8.2156

Corresponding author: Dr. Vivek Singh Kirar

Conflict of interest: No conflict of interest.

\section{Abstract}

Background: Infections in early neonatal period are one of the important factors responsible for high mortality and morbidity in neonates in developing countries. Although it is being frequently observed by pediatricians in neonates, still insufficient relevant studies are documented. The objective of the present study was to evaluate the utility of gastric aspirate cytology as a screening tool for neonatal sepsis, and to determine the polymorphonuclear leukocyte count present in smear of gastric aspirate and correlating it with blood culture proven sepsis.

Methods: The study was conducted on 100 neonates suspected with septicemia in inborn patients in Index medical college hospital and research centre. Gastric aspirate sample was collected within 6 hours of birth for septic screening of neonates. All the collected data was statistically analysed by applying Chi-square test using SPSS 2.0 software.

Results: Gastric aspirate cytology has sensitivity of $53.19 \%$ and specificity of $62.28 \%$ with positive predictive accuracy of $51.33 \%$ and negative predictive accuracy of $63.4 \%$. The relationship between gastric aspirate cytology and maternal risk factors like PROM are found to be highly significant.

Conclusions: We conclude that gastric aspirate cytology in neonates is an excellent screening technique for neonatal sepsis added to a detailed perinatal history and clinical examination. The chances of positivity of gastric aspirate increase as the duration of rupture of membranes increased.

Keywords: Gastric aspirate cytology, Neonatal sepsis, Blood culture, Polymorphonuclear leukocytes.

\section{Introduction}

Neonatal sepsis is a clinical syndrome of bacteraemia characterized by systemic signs and symptoms of infection in the first 28 days of life [1,2]. Early diagnosis and treatment of neonatal sepsis is necessary to prevent serious morbidity and mortality [3]. This study has been designed to determine the polymorphonuclear leukocytes [4,5] count present in smear of gastric aspirate and correlating it with blood culture proven sepsis[6]. Respiratory distress is the most common presentation of neonatal septicaemia. Other features include irritability, lethargy, temperature instability, poor perfusion, hypotension and jaundice with sign of meningitis.

The presence of more than five polymorphs per high power field is correlating with neonatal infection. Blood culture is the gold standard for diagnosis of septicaemia [6] and should be performed in all cases of suspected sepsis prior to starting antibiotics. A positive blood culture with sensitivity of the isolated organism is the best guide to antimicrobial therapy.
Examination of gastric aspirate is a rapid and reliable method of early diagnosis of neonatal sepsis, provided the aspiration is done within an hour of birth [7].

Aim And Objectives:(a) To study the correlation between positive gastric aspirate cytology and blood culture proven sepsis.

(b) For early and effective management of septicemia, to decrease mortality and morbidity.

Methodology: Study design: This was a hospital based prospective study.

Study area: Study was carried out in Department of Pathology in Index Medical College Hospital And Research Centre Indore between February 2020 to March 2021.All newborns with clinical suspicion or risk factors for sepsis were recruited in this study. 
Collection Method: The gastric contents were aspirated within 6 hours of birth using a sterile feeding tube and syringe. The time factor is important because the $\mathrm{pH}$ of gastric juice is alkaline at birth and the increasing acidity of gastric secretion acts as an antiseptic and renders the result fallacious[8].As per Kumar $R$ et al Int J Contemp Pediatr. 2018Jul;5(4):1662-1665[7].(a) The slides will be prepared by using fifty microlitre of centrifuged gastric aspirate was mixed with twenty five microlitre of methylene blue dye. After making a wet preparation it will be examined under light microscope in five fields consecutively and average taken. (b)Two $\mathrm{ml}$ of gastric aspirate in a sterile conical test tube was taken \& centrifuged. One drop was spread on a clean glass slide and was stained with Leishman's stain, slide was examined for polymorphonuclear leukocytes under light microscope at high power field(100x) in five fields and average was taken.

\section{Data Analysis}

Statistical testing was conducted with the statistical package for the social science system SPSS 2.0. Continuous variables are presented as mean $\pm \mathrm{SD}$, and categorical variables are presented as absolute numbers. Data entry was done using MICROSOFT EXCEL 2007.Data analysis was done using EPI.INFO.3.5-3. Data presented as percentages. Chi square tests applied wherever necessary to find out association between variables. $\mathrm{p}>0.05$ was taken as significant.

\section{Neutrophil}

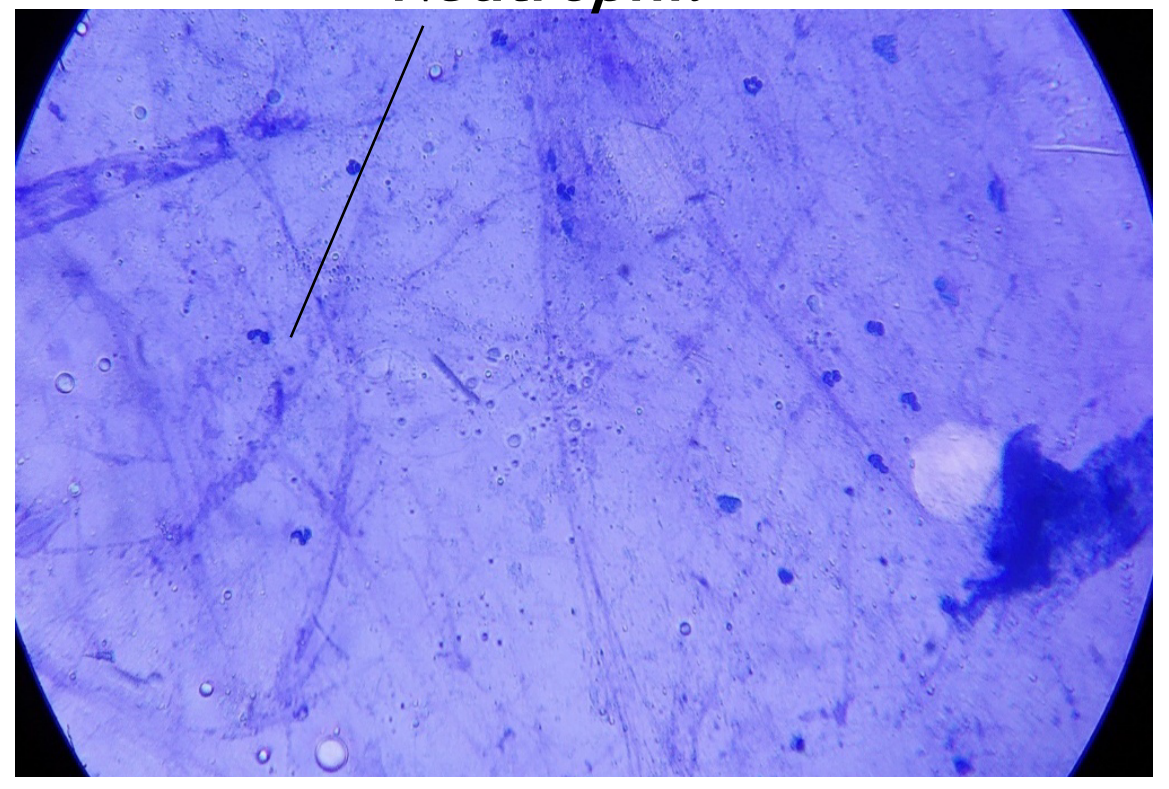

WET PREPRATION OF GASTRIC ASPIRATE

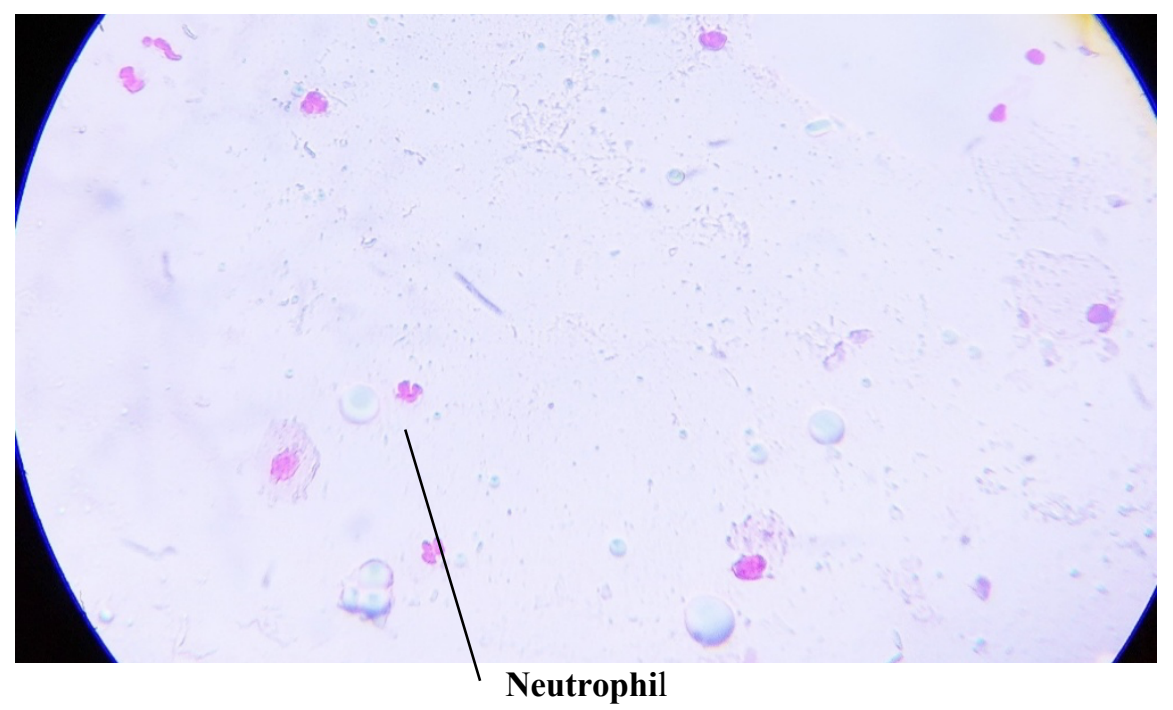




\section{LEISHMAN'S STAIN PREPRATION}

INCLUSION CRITERIA: Neonates with risk factor for sepsis[6]: All neonates born to mother with a history of premature rupture of membrane, Prolonged rupture of membrane ( $>18 \mathrm{hrs})$,Spontaneous preterm onset of labour, $\mathrm{DM}, \mathrm{PIH}$, any other systemic infections.

Neonates with clinical features of sepsis[6]: All neonates with refusal to feeds, Poor cry,fever (axillary temperature of $37.5^{\circ} \mathrm{C}$ or more) $[6,9]$ and hypothermia (axillary temperature less than $35.5^{\circ} \mathrm{C}$.Meconium stained amniotic fluid and /or meconium aspiration syndrome.

Exclusion criteria: Neonates born to mothers who were started on antibiotics prior to procedure[6]. Neonates who were fed (breastfed or other feeds) prior to aspiration of gastric fluid[6].

Results

Table 1: Incidence of sepsis by GAC with maternal risk factor.

\begin{tabular}{|c|c|c|c|}
\hline Maternal risk factors $(n=100)$ & Gastric Aspirate cytology & BLOOD CULTURE POSITIVE & PVALUE \\
\hline PROM (43) & $\begin{array}{l}>5 \text { (positive) } 24 \\
<5 \text { (negative }) 19\end{array}$ & $\begin{array}{l}03 \\
02\end{array}$ & \multirow[t]{7}{*}{0.046} \\
\hline $\begin{array}{l}\text { PROLONG LABOR } \\
\text { (14) }\end{array}$ & \begin{tabular}{|l|} 
Positive 08 \\
Negative
\end{tabular} & $\begin{array}{l}01 \\
02 \\
\end{array}$ & \\
\hline $\begin{array}{l}\text { MSAF } \\
(22)\end{array}$ & $\begin{array}{l}\text { Positive } 15 \\
\text { Negative }\end{array}$ & $\begin{array}{l}05 \\
02\end{array}$ & \\
\hline $\begin{array}{l}\text { PIH } \\
(07)\end{array}$ & $\begin{array}{l}\text { Positive } 04 \\
\text { Negative }\end{array}$ & $\begin{array}{l}03 \\
02\end{array}$ & \\
\hline $\begin{array}{l}\text { DM2 } \\
(04)\end{array}$ & $\begin{array}{l}\text { Positive } 03 \\
\text { Negative }\end{array}$ & $\begin{array}{l}01 \\
01\end{array}$ & \\
\hline $\begin{array}{l}\text { FEBRILE ILLNESS } \\
(07)\end{array}$ & $\begin{array}{l}\text { Positive } 05 \\
\text { Negative }\end{array}$ & $\begin{array}{l}02 \\
01\end{array}$ & \\
\hline $\begin{array}{l}\text { DIARRHOEA } \\
(03)\end{array}$ & $\begin{array}{l}\text { Positive } 02 \\
\text { Negative }\end{array}$ & $\begin{array}{l}01 \\
01\end{array}$ & \\
\hline
\end{tabular}

$P$ value $<\mathbf{0 . 0 5}$, hence association of GAC with blood culture proven sepsis is significant intable 1

PROM (Premature rupture of membranes), MSAF(Meconium Stained Amniotic Fluid), PIH(Pregnancy induced Hypertension),DM2(diabetes Mellitus Type-2).

Table 2: Incidence of sepsis by GAC with gestational age of neonate

\begin{tabular}{|l|l|l|l|}
\hline Gestational age (n=100) & Gastric Aspirate cytology & BLOOD CULTURE P0SITIVE & P VALUE \\
\hline Pre term (28) & $>5$ (positive) 19 & 08 & \multirow{2}{*}{0.39} \\
& $<5$ (negative) 09 & 03 & \\
\hline Late pre term(24) & Positive 16 & 04 \\
& Negative 08 & 03 & \\
\hline Term(21) & Positive17 & 02 \\
& Negative 04 & 01 & \\
\hline Post term(27) & Positive19 & 05 & \\
& Negative08 & 01 & \\
\hline
\end{tabular}

$P$ value $>0.05$, hence association of GAC with proven sepsis with blood culture is not significant in Table 2

Table 3: Incidence of sepsis by GAC with birth weight of neonate.

\begin{tabular}{|l|l|l|l|}
\hline $\begin{array}{l}\text { Birth weight } \\
(\mathbf{n}=\mathbf{1 0 0})\end{array}$ & $\begin{array}{l}\text { Gastric Aspirate } \\
\text { Cytology }\end{array}$ & $\begin{array}{l}\text { BLOOD CULTURE } \\
\text { P0SITIVE }\end{array}$ & \multirow{2}{*}{ P VALUE } \\
\hline $\begin{array}{l}\text { Less than } 2.5 \mathrm{~kg} \\
(43)\end{array}$ & 5(positive) 27 \\
<5(negative) 16 & 08 \\
\hline $\begin{array}{l}\text { More than } 2.5 \mathrm{~kg} \\
(57)\end{array}$ & Positive 31 & 06 \\
\hline & Negative26 & 09 & \multirow{2}{*}{0.081} \\
\hline
\end{tabular}

$P$ value $>0.05$, hence association of GAC with blood culture proven sepsis is not significant in Table 3

Gastric aspirate cytology has sensitivity 0 f $53.19 \%$ and specificity of $62.28 \%$ with positive predictive accuracy of $51.33 \%$ and negative predictive accuracy of $63.4 \%$. 


\section{Discussion:}

Neonatal sepsis is one of the important causes of neonatal mortality. An early diagnosis not only helps in early institution of antibiotic therapy to reduce mortality but also helps in avoiding the unnecessary treatment of non- infected neonates. Although blood culture is the gold standard in diagnosis, it takes time and often complicated and has low yield [10]. The readily achievable complete blood count and the differential leukocyte count have a relatively poor specificity for diagnosing sepsis.

Examination of the gastric aspirate in a newborn for cells and bacteria has been claimed to be a simple and accurate screening test for the diagnosis of septicemia [11]. It is assumed that gastric polymorphs represent a fetal intraamniotic inflammatory response. Therefore from the above study it is proved that there is a correlation of gastric aspirate cytology and rupture of membranes[12] ( $p$ value 0.046).No significant correlation in positivity of gastric aspirate cytology with gestational age, and birth weight was documented in our study.

\section{Conclusion:}

Neonatal sepsis is one of the major causes of neonatal mortality and morbidity. High index of suspicion helps in arriving at early diagnosis and appropriate management. Gastric aspirate cytology as a screening tool for neonatal sepsis with intermediate sensitivity, specificity, positive predictive value and negative predictive values serves as a good tool, added to a detailed antenatal history and clinical examination of the neonate. The value of gastric aspirate cytology as a screening tool for neonatal sepsis increases, when it is used in conjunction with blood culture.

\section{References:}

1. Liu L, Oza S, Hogan D, Perin J, Rudan I, Lawn JE, et al. Global, regional, and national causes of child mortality in 2000-13, with projections to inform post-2015 priorities: an updated systematic analysis Lancet.2015;385(9966):430-40.

2. Bang AT, Bang RA, Baitule SB, Reddy MH, Deshmukh MD. Effect of home-based neonatal care and management of sepsis on neonatal mortality: Field trial in rural India. Lancet. 1999;354(9194):1955-61

3. Camacho-Gonzalez A, Spearman PW, Stoll BJ. Neonatal infectious disease: evaluation of neonatal sepsis.Pediatr Clin North Am. 2013;60:367-89.

4. Yeyung CY, Tan AY. Gastric aspirate finding in neonatal pneumonia. Am Dis Child. 2004;4(7):735- 6.

5. Mishra PK, Shanna B, Malik CK, Agarwal SK. Simple test of early detections of neonatal infections. Ind Paediatr. 2007;20:447-8.

6. International Journal of Contemporary Pediatrics Kumar $\mathrm{R}$ et al. Int J ContempPediatr. 2018 Jul;5(4):1662-1665

7. Yadav $\mathrm{M}$ et al. Int J Comtemp Pediatric 2018 Nov:5(6): 2309-2313

8. Adler SM, Deuton RL. J Pediatr. 2007;86(6):942-

9. Lutsar I, Chazallon C, Carducci FI, Trafojer U, Abdelkader B, de Cabre VM, Esposito S, Giaquinto C, Heath PT, Ilmoja ML, Katragkou A, Lascoux C, Metsvaht T, Mitsiakos G, Netzer E, Pugni L, Roilides E, Saidi Y, Sarafidis K, Sharland M, Usonis V, Aboulker JP, NeoMero Consortium. Current management of late onset neonatal bacterial sepsis in five European countries. Eur J Pediatr. 2014;173(8):997-1004.

10. Escobar GJ. What have we learned from observational studies on neonatal sepsis? PediatCrit Care Med. 2005;6(3):S138-45. 6. Ramos JK, Takkar

11. Parida SN, Verma IC, Thomas S. Evaluation of m-ESR in diagnosis of neonatal sepsis. Indian $\mathrm{J}$ Paediatr. 2007(4);7:381-4.

12. Ramos JK, Takkar VP, Bhakoo NA. Scoring system for prediction of early neonatal infection. Ind Pediatr. 2012;11:597. 